\title{
Association between spousal emotional abuse and reproductive outcomes of women in India: findings from cross- sectional analysis of the 2005-2006 National Family Health Survey
}

Sucheta Tiwari, $1 \square$

Email sucheta.tiwari@gmail.com

Ron Gray, 2

Crispin Jenkinson, 3

Claire Carson, 4

1 Department of Psychiatry, Lady Hardinge Medical College, New Delhi, India

2 National Perinatal Epidemiology Unit, University of Oxford, Oxford, UK

3 Health Services Research Unit, Nuffield Department of Population Health, University of Oxford, Oxford, UK

4 National Perinatal Epidemiology Unit, University of Oxford, Oxford, UK

Received: 30 January 2017 / Accepted: 28 February 2018

\section{Abstract \\ Purpose}

Spousal violence against women is a global public health problem. In India, approximately $40 \%$ of women report spousal violence. Like physical and sexual violence, emotional violence may be a determinant of women's health. This study explores the association between exposure to spousal emotional abuse and poor reproductive outcomes in Indian women. 
Data on 60,350 women, collected in the Third Indian National Family Health Survey were analysed to assess the impact of spousal emotional abuse on seven reproductive outcomes: age at first birth, number of children, terminated pregnancies, unwanted pregnancies, access to prenatal and skilled delivery care, and breastfeeding. Spousal emotional abuse was assessed using two overlapping constructs: emotional violence and controlling behaviour. Multivariable logistic regression was used for analysis.

\section{Results}

Spousal emotional violence and controlling behaviour was reported by 16 and $38 \%$ of the women, respectively. In unadjusted analyses, spousal emotional violence was associated with all adverse reproductive outcomes, except breastfeeding. Controlling for socio-demographic risk factors attenuated the association, and further adjustment for other forms of violence removed all significant associations. Spousal controlling behaviour was significantly associated with all outcomes, except breastfeeding. The effects remained statistically significant in multivariable regression.

$\mathrm{AQ} 4$

AQ5

\section{Conclusions}

Women's experience of violence may be under-reported. When other forms of violence were adjusted for, emotional violence was not associated with adverse reproductive outcomes, whereas controlling behaviour remained associated with all but one adverse reproductive outcome. Therefore, spousal controlling behaviour requires further investigation as a determinant of reproductive health.

\section{Keywords}

Emotional abuse

Intimate partner violence

Women's health

India

Reproductive health 


\section{Introduction}

Violence against women is widely regarded as a global public health problem [1, 2]. Evidence indicates that most incidents of violence against women happen in the home, with spouses or partners being the most common perpetrators $[2,3]$. Intimate partner violence (IPV) can take the form of physical or sexual violence, or of psychological or emotional abuse. Emotional abuse can comprise humiliation, controlling behaviour, isolating a woman from her friends or family, denying her access to basic resources and deliberately belittling her [4]. The estimated prevalence of psychological or emotional partner abuse ranges from 20 to $75 \%$ across the world, and is commonly present with other forms of violence. Some victims report that emotional abuse is, at times, perceived to be a greater torment than physical or sexual abuse [5].

Exposure to IPV can have immediate and long-term physical and psychological health effects on women and their families $[5,6]$. Both emotional abuse and coercive, controlling behaviour from the spouse have been described as forms of psychological abuse women experience [7]. Global estimates of the influence of IPV on health do not usually take emotional abuse into account. The reasons cited for leaving out emotional abuse are that there is no single cross-cultural definition of emotional abuse, and no cross-culturally acceptable measure exists $[1,5]$. However, it could be argued that there is a greater need to address the issue of clearly defining emotional abuse in various cultural contexts and assessing health effects it might have.

Physical and sexual IPV has previously been found to be associated adverse reproductive outcomes, including unintended pregnancies [8]. The associated loss of autonomy and control is a form of emotional abuse that limits women's reproductive choices and can lead to poor reproductive outcomes [9, 10,11]. Lower autonomy, assessed in the domains of control over finances, decision making power, and freedom of movement, has previously been seen to be associated with poor access to antenatal care services in India [9]. While women who experience intimate partner physical and sexual violence have also been seen to have babies with lower birth weights, have poor gestational weight gain, increased perinatal and neonatal deaths, and lesser breastfeeding [8], the evidence for the impact of emotional abuse on these outcomes is more limited. The previous studies measuring nonphysical or psychological partner abuse have found associations with sexually transmitted infections, chronic pelvic pain, and low birth weight of full-term neonates, suggesting that emotional abuse has a role to play in women's reproductive health $[12,13]$. 
There is substantial evidence of widespread violence against women in India $[14,15,16]$. IPV during pregnancy is associated with adverse reproductive outcomes and behaviours $[17,18,19]$ and, while the impact of physical and sexual violence on unwanted pregnancies and child health has been explored $[20,21]$, to our knowledge, there has been no study that focussed on the role of exposure to emotional abuse in affecting reproductive health of Indian women. In this paper, we examine the association between spousal emotional abuse throughout a woman's life and a broad range of reproductive outcomes and behaviours among Indian women, using the cohort from the third Indian National Family Health Survey.

\section{Methods}

\section{Data source}

The National Family Health Surveys are country-wide cross-sectional surveys conducted with a representative sample of households throughout India that provide a demographic and health database for the country. These use standardised questionnaires, sample designs, and field procedures to collect data in different settings [22]. The NFHS-3 provides the most recent country-level information for India on spousal domestic violence as well as reproductive health outcomes. All the details about the survey procedure and final reports have been made available online [22]. NFHS-3 collected information from a nationally representative sample of 124,385 women belonging to 109,041 households.

A multi-stage stratified sampling method was used for this survey. Details of the stratification techniques used are available online [22]. At the rural level, twostage sampling was done. The 2001 Census list of villages served as the sampling frame. In the first stage, villages, which were the Primary Sampling Units (PSUs), were selected with probability proportional to population size (PPS). In the second stage, households were randomly selected from these PSUs. In the urban areas, sampling was conducted in three stages. In the first stage, wards were selected with PPS. In the next stage, one census enumeration block (CEB) was randomly selected from each sample ward. In the third and final stages, households were randomly selected from each selected CEB.

Interviews were conducted with all women aged 15-49 years who were usual residents of the selected household or visitors who stayed in the household the night before the survey [23]. While the women's questionnaire was given to every woman in the selected households, the domestic violence module was administered to only one eligible woman randomly selected in each selected 
household. The interviews were completed only if they could be conducted in complete privacy without interruption from other household members. To maximise the representativeness of the data and to account for unequal probability of selection or differential response rates, national and state-level weights were devised. An additional set of domestic violence weights were calculated to ensure representativeness of the sub-sample of women selected for the domestic violence module [23].

For this study, the sample was restricted to the subset of women who were selected for the domestic violence module of the survey and had ever been married and pregnant. See Fig. 1 for details of the study population, detailing the exclusions applied.

\section{Fig. 1}

Flow chart to show the study population 
Total number of women interviewed in NFHS-3.

$(124,385)$

Women not selected for the domestic violence module. $(40,682)$

Women selected for the domestic violence module. $(83,703)$

Interview interrupted/ not completed. $(3,577)$

Interview completed without interruption.

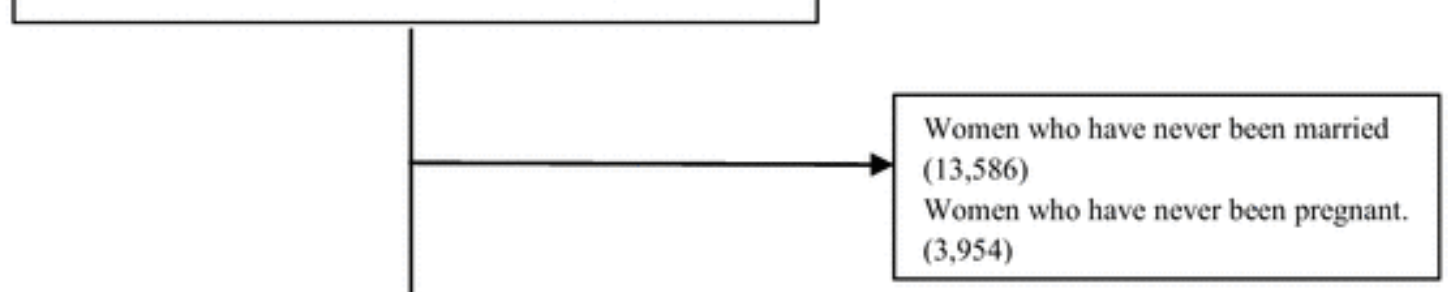

Women who have been married and pregnant.

$\mathrm{N}=62,586$ ELIGIBLE women

Full data on violence questions

$\mathrm{N}=62,545$

Full data on violence questions and key confounding and moderating variables,

$\mathrm{N}=60,350$ (used for analysis of life long reproductive outcomes)
Pregnant in the last 5 years?

Yes, $\mathrm{N}=27,543$

\section{Emotional abuse variables}




\section{Spousal emotional violence}

The NFHS-3 used a shortened and modified version of the revised Conflict Tactics Scale (CTS-2) to assess exposure to spousal violence among survey participants. The Conflict Tactics Scale has been widely in use since the 1970s in a wide variety of cultural settings. The scale has good reliability (alpha ranging from 0.79 to 0.95 ), and there is good evidence for construct and discriminant validity in a variety of cultural settings [24]. Questions were asked to ascertain three forms of spousal violence ever inflicted upon women: emotional, physical, and sexual spousal violence. The questions which are asked to determine exposure to different types of spousal violence are summarized in Table 1. These questions were used to derive an 'ever-experienced emotional violence' variable, coded yes $=1$ (women responded yes to any of the three EV questions), and no $=0$ (women responded no to all $\mathrm{EV}$ questions).

\section{Table 1}

Spousal violence questions used in this survey

(Does/ did) your (last) husband ever do any of the following things to you?

(a) Slap you

(b) Twist your arm or pull your hair

(c) Push you, shake you, or throw something at you

(d) Punch you with his fist or with something that could hurt you

(e) Kick you, drag you or beat you up

(f) Try to choke you or burn you on purpose

(g) Threaten or attack you with a knife, gun, or any other weapon

(h) Physically force you to have sexual intercourse with him even when you did not want to

(i) Force you to perform any sexual acts you did not want to

(j) Say or do something to humiliate you in front of others

(k) Threaten to hurt or harm you or someone close to you
(Physical violence)

(Physical violence)

(Physical violence)

(Physical violence)

(Physical violence)

(Physical violence)

(Physical violence)

(Sexual violence)

(Sexual violence)

(Emotional violence)

(Emotional violence) 
(Does/ did) your (last) husband ever do any of the following things to you?

(1) Insult you or make you feel bad about yourself

Spousal controlling behaviour

The survey also included questions on spousal controlling behaviour, as an important aspect of emotional abuse. These questions were used to derive a variable denoting the extent of controlling behaviours, coded $0,1,2$, and $\geq 3$ types of controlling behaviour reported (summarized in Table 2).

\section{Table 2}

Spousal controlling behaviour questions used in the survey

Husband jealous if respondent talks with other men

Husband accuses respondent of unfaithfulness

Husband does not permit respondent to meet her girl friends

Husband tries to limit respondent's contact with family

Husband insists on knowing where respondent is

Husband does not trust respondent with money

\section{Study outcomes}

Two sets of outcomes were analysed in this study. The first set measured reproductive outcomes over women's reproductive life to date. These included having a first birth under 18 years of age, reporting any termination of pregnancy, and having borne more than two children. Two children were chosen as the threshold, because a majority of Indian women of the reproductive age group report that they do not want to bear more than two children, and a target total fertility rate of 2.1 was decided upon by a national population policy [25, 26]. All women were included in this analysis $(n=60,350)$.

The second set of outcomes was based on information collected about pregnancies in the 5 years preceding the interview. These included unwanted pregnancies in the last 5 years, breastfeeding (indicating whether the children born in the last 5 years had been breastfeed for at least 1 month), and utilisation of antenatal care and skilled delivery care for the study participant's last pregnancy. Women who reported a pregnancy in the last 5 years were included $(n=26,487)$. 


\section{Potential confounding factors}

Socio-ecological models proposed by Krug et al. and Swahnberg et al. which influence exposure to spousal violence were explored for plausible independent associations with poor reproductive outcomes [6,27]. The socio-economic and demographic factors that have been shown to influence IPV in large-scale studies and can also have independent, plausible associations with poor reproductive health were included as potential confounding factors [1, 4, 28]. These were then included in the regression models analysing spousal emotional violence and birth outcomes. The potential confounding factors included in the multivariable regression models were age of the women $(15-19,20-24,25-29$, 30-34, 35-39, 40-44, and 45-49 years), level of education of women (no education, primary education, secondary education or higher education) and of their partners (same groups), employment status of the women (employed/unemployed at the time of the interview), religion (Hindu, Muslim, Christian, other), caste (Scheduled Caste, Scheduled Tribe, Other Backward Classes, others, as defined in the Indian Constitution), and wealth quintile that the selected women's household belonged to (where group one was the poorest and group five was the richest group). Finally, the presence of other forms of spousal violence, either physical or sexual, was considered as a co-variate in the analyses.

\section{Statistical methods}

The prevalence of spousal emotional violence was determined. The demographic and socio-economic characteristics of the study population were described, by exposure groups. Unadjusted odds ratios were obtained using logistic regression. The effect of exposure to spousal emotional violence and spousal controlling behaviours on reproductive outcomes of interest was analysed separately. Multivariable logistic regression was then performed in which potential confounding variables (as listed above) were included. All these confounders were included on theoretical grounds regardless of statistical significance, as it is known that the significance of association with the outcome is not the sole determinant of the degree of confounding [28, 29]. Analyses were conducted in two stages, first adjusting for socio-demographic and economic covariates, and then final models including variables indicating any reported sexual or physical violence. All analyses were completed using the survey commands in STATA version 13 (STATA Corp, College Station, USA), which accounts for the clustered, stratified design of the study [30]. All reported percentages and odds ratios are weighted using survey commands and all reported sample sizes are actual numbers of individuals. 


\section{Results}

A summary of the descriptive analysis of demographic and socio-economic characteristics of the sample are presented in Table 3. Of the women analysed for this study, 14\% reported exposure to spousal emotional violence, and only $4 \%$ of them reported exposure to emotional violence in the absence of sexual or physical violence. Among the women included for analysis, 38\% reported exposure to spousal controlling behaviour. Overall, women who reported emotional violence or controlling behaviour from their spouse were more deprived than those who reported no violence. Women who experience emotional violence, and those who report spousal controlling behaviours, tend to be poorer, living in rural areas, and less well educated. A greater proportion of women who experience emotional abuse were employed at the time of assessment. While age was not significantly different between women who experience emotional violence and those who did not, there was an association between age and controlling spousal behaviour, with those exposed tending to be younger.

\section{Table 3}

Characteristics of the study population

\begin{tabular}{|l|l|l|l|l|l|l|}
\hline & All & \multicolumn{3}{|l}{ Emotional } \\
violence
\end{tabular}

*Association significant at the 5\% level. Percentages expressed after accounting for domestic violence weights in sample design and may not add up to $100 \%$ in all cases 


\begin{tabular}{|c|c|c|c|c|c|c|c|}
\hline \multirow{3}{*}{$\begin{array}{l}\text { Characteristics, } \\
N(\%)\end{array}$} & \multirow[t]{2}{*}{ All } & \multicolumn{2}{|c|}{$\begin{array}{l}\text { Emotional } \\
\text { violence }\end{array}$} & \multicolumn{4}{|c|}{ Controlling behaviours } \\
\hline & & No & Yes & No & 1 type & $\begin{array}{l}2 \\
\text { types }\end{array}$ & $\begin{array}{l}\geq 3 \\
\text { types }\end{array}$ \\
\hline & $\begin{array}{l}60,350 \\
(100 \%)\end{array}$ & $\begin{array}{l}51,809 \\
(86 \%)\end{array}$ & $\begin{array}{l}8,541 \\
(14 \%)\end{array}$ & $\begin{array}{l}37,125 \\
(62 \%)\end{array}$ & $\begin{array}{l}9,630 \\
(16 \%)\end{array}$ & $\begin{array}{l}7,369 \\
(12 \%)\end{array}$ & $\begin{array}{l}6,226 \\
(10 \%)\end{array}$ \\
\hline Urban & 31.3 & 32.3 & 26.3 & 34.9 & 27.5 & 26.7 & 24.9 \\
\hline Rural & 68.7 & 67.7 & 73.8 & 65.1 & 72.5 & 73.3 & 75.2 \\
\hline $\begin{array}{l}\text { Education: } \\
\text { woman }\end{array}$ & & * & & * & & & \\
\hline None & 48.9 & 46.9 & 59.2 & 44.1 & 55.5 & 52.5 & 57.9 \\
\hline Primary & 15.2 & 14.8 & 16.8 & 14.9 & 14.6 & 15.6 & 16.9 \\
\hline Secondary & 30.6 & 32.2 & 22.2 & 33.8 & 26.7 & 28.1 & 23.3 \\
\hline Higher & 5.4 & 6.1 & 1.9 & 7.2 & 3.1 & 3.8 & 1.9 \\
\hline $\begin{array}{l}\text { Education: } \\
\text { partner }\end{array}$ & & * & & * & & & \\
\hline None & 27.4 & 25.8 & 35.9 & 24.6 & 30.8 & 29.6 & 33.4 \\
\hline Primary & 16.2 & 15.6 & 19.3 & 15.3 & 17.1 & 16.8 & 18.6 \\
\hline Secondary & 44.4 & 45.5 & 38.3 & 45.8 & 42.6 & 43.7 & 40.5 \\
\hline Higher & 11.3 & 12.4 & 5.7 & 13.6 & 8.8 & 9.2 & 6.5 \\
\hline $\begin{array}{l}\text { Wealth Index } \\
\text { (quintiles) }\end{array}$ & & * & & * & & & \\
\hline Poorest & 31.6 & 29.8 & 41.1 & 27.3 & 36.3 & 35.6 & 41.1 \\
\hline Poorer & 22.7 & 22.1 & 25.8 & 21.5 & 23.7 & 24.2 & 25.8 \\
\hline Middle & 17.9 & 18.1 & 16.5 & 18.9 & 16.9 & 16.7 & 15.7 \\
\hline Richer & 15.1 & 16.0 & 10.6 & 16.8 & 14.0 & 12.8 & 11.1 \\
\hline Richest & 12.7 & 13.9 & 6.1 & 15.5 & 9.2 & 10.7 & 6.3 \\
\hline Religion & & & & $*$ & & & \\
\hline Hindu & 83.0 & 83.0 & 82.9 & 83.5 & 82.8 & 82.2 & 82.1 \\
\hline Muslim & 11.5 & 11.4 & 12.0 & 10.6 & 12.6 & 12.6 & 12.9 \\
\hline Christian & 2.2 & 2.2 & 1.9 & 2.6 & 1.7 & 1.3 & 1.6 \\
\hline Other & 3.3 & 3.3 & 3.1 & 3.3 & 2.9 & 3.9 & 3.5 \\
\hline
\end{tabular}

*Association significant at the 5\% level. Percentages expressed after accounting for domestic violence weights in sample design and may not add up to $100 \%$ in all cases 


\begin{tabular}{|c|c|c|c|c|c|c|c|}
\hline \multirow{3}{*}{$\begin{array}{l}\text { Characteristics, } \\
N(\%)\end{array}$} & \multirow[t]{2}{*}{ All } & \multicolumn{2}{|c|}{$\begin{array}{l}\text { Emotional } \\
\text { violence }\end{array}$} & \multicolumn{4}{|c|}{ Controlling behaviours } \\
\hline & & No & Yes & No & 1 type & $\begin{array}{l}2 \\
\text { types }\end{array}$ & $\begin{array}{l}\geq 3 \\
\text { types }\end{array}$ \\
\hline & $\begin{array}{l}60,350 \\
(100 \%)\end{array}$ & $\begin{array}{l}51,809 \\
(86 \%)\end{array}$ & $\begin{array}{l}8,541 \\
(14 \%)\end{array}$ & $\begin{array}{l}37,125 \\
(62 \%)\end{array}$ & $\begin{array}{l}9,630 \\
(16 \%)\end{array}$ & $\begin{array}{l}7,369 \\
(12 \%)\end{array}$ & $\begin{array}{l}6,226 \\
(10 \%)\end{array}$ \\
\hline \multicolumn{2}{|c|}{ Woman in employment } & $*$ & & $*$ & & & \\
\hline No & 61.9 & 63.5 & 53.5 & 63.0 & 61.1 & 62.2 & 57.8 \\
\hline Yes & 38.1 & 36.5 & 46.5 & 37.0 & 38.9 & 37.8 & 42.2 \\
\hline Caste & & $*$ & & $*$ & & & \\
\hline Scheduled caste & 19.7 & 18.8 & 24.4 & 18.4 & 20.1 & 21.4 & 23.5 \\
\hline Scheduled tribe & 8.2 & 7.8 & 10.5 & 7.6 & 8.1 & 8.6 & 10.8 \\
\hline $\begin{array}{l}\text { Other backward } \\
\text { classes }\end{array}$ & 40.8 & 40.9 & 40.1 & 41.9 & 42.1 & 36.5 & 38.4 \\
\hline None & 31.3 & 32.5 & 25.0 & 32.1 & 29.7 & 33.5 & 27.4 \\
\hline
\end{tabular}

\section{Impact of spousal emotional violence}

Table 4 shows the results of the logistic regression analyses. In unadjusted analyses, women who reported spousal emotional violence were significantly more likely to have had a first child before they turned 18 years of age compared to women who had no exposure to such violence (OR 1.46, 95\% CI 1.35-1.57). The findings remained statistically significant after adjusting for potential confounders, although the strength of association decreased (OR 1.19, 95\% CI 1.10-1.28). Once other forms of spousal violence were considered, however, there remained no significant association between spousal emotional violence and a low age at first birth. A similar pattern was observed for the odds having had an unwanted pregnancy in 5 years preceding the survey [unadjusted OR 1.41 (95\% CI 1.27-1.57), adjusted OR 1.07 (95\% CI 0.95-1.21)], and having access to skilled delivery care for pregnancies in the previous 5 years [unadjusted OR 1.76 (95\% CI 1.57-1.98), adjusted OR $1.02(0.87,1.18)]$.

\section{Table 4}

Effect of spousal emotional violence and spousal controlling behaviours, on women's reproductive health outcomes 


\begin{tabular}{|c|c|c|c|c|}
\hline \multirow[t]{2}{*}{ Outcome } & \multirow{2}{*}{ 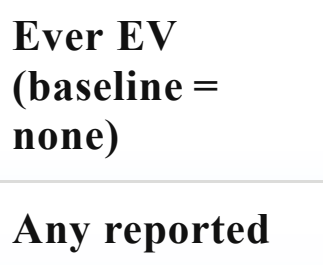 } & \multicolumn{3}{|c|}{$\begin{array}{l}\text { Controlling behaviours reported }(\text { baseline }=\text { no } \\
\text { controlling behaviours reported) }\end{array}$} \\
\hline & & 1 issue & 2 issues & 3 or more \\
\hline \multicolumn{5}{|c|}{ Life-long adverse outcomes } \\
\hline \multicolumn{5}{|c|}{ First birth at $<18$ years of age } \\
\hline Unadjusted & $\begin{array}{l}1.46(1.35 \\
1.57)^{*}\end{array}$ & $\begin{array}{l}1.25(1.16 \\
1.34)^{*}\end{array}$ & $\begin{array}{l}1.29(1.19- \\
1.4)^{*}\end{array}$ & $\begin{array}{l}1.66(1.52 \\
1.82)^{*}\end{array}$ \\
\hline $\begin{array}{l}\text { Plus } \\
\text { confounders }\end{array}$ & $\begin{array}{l}1.19 \\
(1.10,1.28)^{*}\end{array}$ & $\begin{array}{l}1.03 \\
(0.96,1.12)\end{array}$ & $\begin{array}{l}1.10 \\
(1.02,1.2)^{*}\end{array}$ & $\begin{array}{l}1.27 \\
(1.15,1.39)^{*}\end{array}$ \\
\hline $\begin{array}{l}\text { Plus other } \\
\text { violence }\end{array}$ & $1.09(1.00,1.18)$ & $\begin{array}{l}1.00 \\
(0.92,1.08)\end{array}$ & $\begin{array}{l}1.07 \\
(0.98,1.17)\end{array}$ & $\begin{array}{l}1.19 \\
(1.08,1.31)^{*}\end{array}$ \\
\hline \multicolumn{5}{|c|}{ Termination of pregnancy (any) } \\
\hline Unadjusted & $\begin{array}{l}1.27 \\
(1.17,1.37)^{*}\end{array}$ & $\begin{array}{l}1.06 \\
(0.98,1.16)\end{array}$ & $\begin{array}{l}1.01 \\
(0.92,1.11)\end{array}$ & $\begin{array}{l}1.23 \\
(1.11,1.36)^{*}\end{array}$ \\
\hline $\begin{array}{l}\text { Plus } \\
\text { confounders }\end{array}$ & $\begin{array}{l}1.33 \\
(1.22,1.44)^{*}\end{array}$ & $\begin{array}{l}1.10 \\
(1.01,1.2)^{*}\end{array}$ & $\begin{array}{l}1.04 \\
(0.94,1.14)\end{array}$ & $\begin{array}{l}1.30 \\
(1.18,1.45)^{*}\end{array}$ \\
\hline $\begin{array}{l}\text { Plus other } \\
\text { violence }\end{array}$ & $1.00(0.92,1.10)$ & $\begin{array}{l}0.99 \\
(0.91,1.09)\end{array}$ & $\begin{array}{l}0.94 \\
(0.85,1.04)\end{array}$ & $1.04(0.94,1.16)$ \\
\hline \multicolumn{5}{|c|}{ Number of children ever born $(>2)$} \\
\hline Unadjusted & $\begin{array}{l}1.40 \\
(1.31,1.50) *\end{array}$ & $\begin{array}{l}1.43 \\
(1.34,1.53)^{*}\end{array}$ & $\begin{array}{l}1.34 \\
(1.24,1.45)^{*}\end{array}$ & $\begin{array}{l}1.35 \\
(1.25,1.46)^{*}\end{array}$ \\
\hline $\begin{array}{l}\text { Plus } \\
\text { confounders }\end{array}$ & $1.06(0.97,1.14)$ & $\begin{array}{l}1.40 \\
(1.29,1.52)^{*}\end{array}$ & $\begin{array}{l}1.27 \\
(1.16,1.39)^{*}\end{array}$ & $\begin{array}{l}1.25 \\
(1.13,1.37)^{*}\end{array}$ \\
\hline $\begin{array}{l}\text { Plus other } \\
\text { violence }\end{array}$ & $0.87(0.80,0.95)$ & $\begin{array}{l}1.33 \\
(1.23,1.44)^{*}\end{array}$ & $\begin{array}{l}1.22 \\
(1.11,1.33)^{*}\end{array}$ & $\begin{array}{l}1.13 \\
(1.02,1.25)^{*}\end{array}$ \\
\hline \multicolumn{5}{|c|}{ Outcomes in last 5 years } \\
\hline \multicolumn{5}{|c|}{ Unwanted pregnancy (any) } \\
\hline Unadjusted & $\begin{array}{l}1.41 \\
(1.27,1.57)^{*}\end{array}$ & $\begin{array}{l}1.20 \\
(1.08,1.35)^{*}\end{array}$ & $\begin{array}{l}1.42 \\
(1.25,1.62)^{*}\end{array}$ & $\begin{array}{l}1.46 \\
(1.27,1.67)^{*}\end{array}$ \\
\hline $\begin{array}{l}\text { Plus } \\
\text { confounders }\end{array}$ & $\begin{array}{l}1.32 \\
(1.18,1.47)^{*}\end{array}$ & $\begin{array}{l}1.13 \\
(1.01,1.27)^{*}\end{array}$ & $\begin{array}{l}1.37 \\
(1.20,1.56)^{*}\end{array}$ & $\begin{array}{l}1.37 \\
(1.19,1.58)^{*}\end{array}$ \\
\hline $\begin{array}{l}\text { Plus other } \\
\text { violence }\end{array}$ & $1.07(0.95,1.21)$ & $\begin{array}{l}1.05 \\
(0.94,1.18)\end{array}$ & $\begin{array}{l}1.27 \\
(1.11,1.45)^{*}\end{array}$ & $\begin{array}{l}1.17 \\
(1.01,1.36)^{*}\end{array}$ \\
\hline \multicolumn{5}{|c|}{ Access to prenatal care (no) } \\
\hline Unadjusted & $\begin{array}{l}1.52 \\
(1.33,1.73)^{*}\end{array}$ & $\begin{array}{l}1.69 \\
(1.48,1.92)^{*}\end{array}$ & $\begin{array}{l}1.71 \\
(1.47,1.99)^{*}\end{array}$ & $\begin{array}{l}2.23 \\
(1.91,2.62)^{*}\end{array}$ \\
\hline
\end{tabular}




\begin{tabular}{|c|c|c|c|c|}
\hline \multirow[t]{2}{*}{ Outcome } & \multirow{2}{*}{$\begin{array}{l}\begin{array}{l}\text { Ever EV } \\
\text { (baseline = } \\
\text { none) }\end{array} \\
\text { Any reported }\end{array}$} & \multicolumn{3}{|c|}{$\begin{array}{l}\text { Controlling behaviours reported }(\text { baseline }=\text { no } \\
\text { controlling behaviours reported) }\end{array}$} \\
\hline & & 1 issue & 2 issues & 3 or more \\
\hline $\begin{array}{l}\text { Plus } \\
\text { confounders }\end{array}$ & $1.14(0.99,1.31)$ & $\begin{array}{l}1.35 \\
(1.17,1.54)^{*}\end{array}$ & $\begin{array}{l}1.42 \\
(1.21,1.67)^{*}\end{array}$ & $\begin{array}{l}1.68 \\
(1.40,2.00)^{*}\end{array}$ \\
\hline $\begin{array}{l}\text { Plus other } \\
\text { violence }\end{array}$ & $0.95(0.81,1.11)$ & $\begin{array}{l}1.27 \\
(1.11,1.46)^{*}\end{array}$ & $\begin{array}{l}1.35 \\
(1.15,1.60)^{*}\end{array}$ & $\begin{array}{l}1.53 \\
(1.27,1.85)^{*}\end{array}$ \\
\hline \multicolumn{5}{|c|}{ Skilled delivery care (no) } \\
\hline Unadjusted & $\begin{array}{l}1.76 \\
(1.57,1.98)^{*}\end{array}$ & $\begin{array}{l}1.63 \\
(1.46,1.83)^{*}\end{array}$ & $\begin{array}{l}1.50 \\
(1.31,1.71)^{*}\end{array}$ & $\begin{array}{l}2.13 \\
(1.86,2.44)^{*}\end{array}$ \\
\hline $\begin{array}{l}\text { Plus } \\
\text { confounders }\end{array}$ & $\begin{array}{l}1.18 \\
(1.03,1.35)^{*}\end{array}$ & $\begin{array}{l}1.23 \\
(1.08,1.39)^{*}\end{array}$ & $\begin{array}{l}1.15 \\
(0.99,1.33)\end{array}$ & $\begin{array}{l}1.35 \\
(1.16,1.57)^{*}\end{array}$ \\
\hline $\begin{array}{l}\text { Plus other } \\
\text { violence }\end{array}$ & $1.02(0.87,1.18)$ & $\begin{array}{l}1.17 \\
(1.03,1.33)^{*}\end{array}$ & $\begin{array}{l}1.10 \\
(0.95,1.28)\end{array}$ & $\begin{array}{l}1.23 \\
(1.05,1.44)^{*}\end{array}$ \\
\hline \multicolumn{5}{|c|}{ Breastfeeding (<1 month) } \\
\hline Unadjusted & $1.19(0.93,1.52)$ & $\begin{array}{l}0.92 \\
(0.73,1.16)\end{array}$ & $\begin{array}{l}0.97 \\
(0.72,1.31)\end{array}$ & $1.12(0.84,1.48)$ \\
\hline $\begin{array}{l}\text { Plus } \\
\text { confounders }\end{array}$ & $1.19(0.93,1.53)$ & $0.9(0.72,1.14)$ & $\begin{array}{l}0.97 \\
(0.72,1.30)\end{array}$ & $1.10(0.82,1.46)$ \\
\hline $\begin{array}{l}\text { Plus other } \\
\text { violence }\end{array}$ & $1.20(0.92,1.57)$ & $0.9(0.71,1.14)$ & $\begin{array}{l}0.96 \\
(0.71,1.30)\end{array}$ & $1.07(0.81,1.41)$ \\
\hline
\end{tabular}

The odds of having had a termination of pregnancy increased slightly after adjustment for socio-demographic confounding factors [unadjusted OR 1.27 (95\% CI 1.17-1.37), adjusted OR 1.33 (95\% CI 1.22-1.44)]. However, once other forms of spousal violence were adjusted for, there remained no significant association between exposure to spousal emotional violence and higher odds of having a terminated pregnancy.

No association was found between exposure to spousal emotional violence and the odds of short duration of breastfeeding (less than 1 month or not initiating). No statistically significant association between exposure to spousal emotional violence and having borne more than two children or access to prenatal care remained after adjusting for potential confounding factors.

\section{Impact of spousal controlling behaviour}


Reported spousal controlling behaviour was more strongly associated with adverse reproductive outcomes than reported emotional violence. In addition, the experience of more controlling behaviours from a spouse was associated with poorer outcomes which remained statistically significant after adjusting for socio-demographic confounding factors, and spousal sexual and physical violence.

The unadjusted odds of having a first birth before the age of 18 were higher among women exposed to controlling behaviours from their spouse, and were highest among those experiencing spousal control in three or more issues compared to those without any experience of spousal controlling behaviours [unadjusted OR single issue 1.25 (95\% CI 1.19-1.40) and unadjusted OR three or more issues 1.66 (95\% CI 1.52-1.82)]. However, the association between experiencing one or two control issues and birth under 18 years was no longer significant when adjusted for socio-demographic confounding factors and spousal sexual or physical violence, respectively. Women experiencing three or more spousal controlling behaviours had significantly higher odds of having had a pregnancy before the age of 18 compared to women who did not experience such behaviours even after adjusting for socio-demographic confounding variables and spousal sexual or physical violence [OR 1.19 (95\% CI 1.08-1.31)].

Other reproductive outcomes which remained statistically significant in the adjusted analysis among women who experienced three or more controlling behaviours from their spouses were: having had more than two children, having an unwanted pregnancy in the previous 5 years, poor access to prenatal and skilled delivery care in the previous 5 years. Breastfeeding was not affected by spousal controlling behaviours.

\section{Discussion}

Emotional violence and controlling behaviours both appear to be associated with adverse reproductive outcomes in the unadjusted analyses, an association which is substantially attenuated after adjusting for age and indicators of socioeconomic inequality. Few women reported emotional violence in the absence of spousal physical or sexual violence. However, controlling behaviours, while associated with other forms of violence, remained independently associated with adverse reproductive outcomes even after taking reported sexual and physical violence into account.

\section{Characteristics of women reporting emotional abuse}


Spousal emotional abuse, in the form of emotional violence and controlling behaviours, is associated with socio-economic disadvantage. Poorer women, those with lower educational attainment, women from a 'backward' caste, and those living in rural areas, were all more likely to report spousal emotional violence and controlling behaviours. Men's educational attainment was also associated with spousal emotional abuse, with women with less well-educated spouses reporting more emotional abuse. The observed association between socio-economic disadvantage and emotional abuse is consistent with findings from other parts of the world [5].

The effect of women's age was inconsistent, with no observed association with $\mathrm{EV}$, while women experiencing controlling behaviours tended to be younger. The relationship of IPV with age of the victim is inconsistent in the literature. Some studies show an increase in partner violence in relation to age. This may be because older age could lead to longer potential exposure to violence [1, 31]. Alternately, age may confer a higher status to women and can be protective in some cases [15, 32]. Similar inconsistency is seen in the association between employment status of women and exposure to spousal violence. It has been suggested that employment can be empowering for women and can reduce the exposure to violence [33]. Conversely, the empowerment which it confers may be seen as threatening to the power balance in the relationship and can lead to an increase in violence, as seen in India and Kenya [23, 34]. This study found a higher likelihood of employment among women exposed to spousal emotional abuse, consistent with the latter proposition. In our study, population women who were in the poorest quintiles were more likely to work outside the home, suggesting that employment status is capturing another aspect of poverty.

Although reported spousal emotional violence was more or less equally distributed across women of different religions, it was seen that spousal controlling behaviour was more frequently reported by Muslim women. On the surface, it may appear that this reflects the traditional Islamic practices which limit women's autonomy. However, findings from other studies which show regional, social, and cultural variations account for the apparent lack of autonomy among Muslim women, more than religion itself does [10, 35]. The data set used for this analysis did not permit further exploration of this association. Further work may be designed to explore whether this is a generalizable finding in the Indian context, and if so, what may be the reasons for this association.

\section{Emotional abuse and reproductive outcomes}


The definition and measurement of emotional abuse are matters of continuous debate $[1,5]$. Our findings suggest that emotional violence as measured by the CTS in this survey is not in itself associated with poor reproductive outcomes, but the broader concept of spousal control is strongly associated with poor reproductive outcomes and access to services. In unadjusted analyses, everreporting emotional violence was associated with all adverse reproductive outcomes, except short duration of breastfeeding. Accounting for confounding of economic and socio-demographic variables attenuated the association, which was then no longer statistically significant for bearing more than two children or access to prenatal care. These findings are consistent with other reports of higher unplanned pregnancy among women with abusive partners, as well as having more termination of pregnancies $[16,18,36]$.

Further adjustment for other forms of violence including physical or sexual violence removed all significant associations with adverse reproductive outcomes. Emotional violence is very rarely present without physical or sexual violence $[5,6]$. Furthermore, exposure to physical as well as sexual violence has adverse psychological consequences [37,38]. As a result, it is difficult to unpick the complex inter-relationships between different forms of abuse, and thus, there is the potential for over-adjustment when including all types of abuse in the models which may mask the true effect emotional abuse has on women's health.

In India, where there is marked gender discrimination and inequality, women are particularly vulnerable to violence at the hands of their spouses [34, 38, 39, 40]. Research suggests that economic empowerment, together with access to higher education, is protective factors reducing the risk of IPV against women in India $[15,34,39]$. However, other factors such as gender inequitable social norms can also have a powerful effect; qualitative research has suggested that both men and women expect some violence to be a socially acceptable part of the marital relationship in India [41], although, at a policy level, IPV is considered wholly unacceptable [42].

Women who experience emotional violence from their partner may have more limited autonomy, due to controlling behaviour by their spouse. Emotional violence can take the form of limiting their access to money, preventing them from working outside the home should they wish to, or limiting their options when it comes to travel or seeking healthcare [32, 40]. In addition, emotional violence in the form of bullying and belittling may destroy a woman's confidence in her own ability and take away her ability to speak up and follow her own wishes. In this way, women may be prevented from seeking contraception or exerting their own control over their family planning (thus explaining the higher proportion of unwanted pregnancies, of a greater than 
desired number of children, and of more termination of pregnancies), or from accessing antenatal or skilled delivery care $[9,10,11,43,44]$. There is evidence to show that victims of partner violence have an increased uptake of medical services overall $[45,46]$. The results reported here suggested a reduction in uptake of prenatal care and skilled birth care in relation to spousal emotional violence.

Care must be taken in the interpretation of these results. Even though women exposed to all forms of spousal violence show greater utilisation of curative services, they are consistently found to have poor utilisation of preventive reproductive health services [17, 43, 46, 47]. In an antenatal clinic-based crosssectional study in England with 500 participants, women who requested for abortion were found to be six times more likely to have experienced physical partner violence, but only $3.6 \%$ of those women attributed the request to partner violence [48]. It is indicative of the fact that quantitative data cannot explain individual and socio-cultural perceptions of the effects of spousal violence.

There has been much debate over the value of screening for domestic violence in health care settings with inconclusive outcomes [49]. Very few studies have been done to assess the effectiveness of such screening programmes in health care settings in India. Researchers have explored the use of maternity centres as appropriate settings for screening domestic violence [50], but our findings show that utilisation of prenatal care and skilled delivery care reduces with exposure to spousal violence. Other studies have shown similar results with exposure to violence during pregnancy $[41,43]$. This brings into question the usefulness of screening for violence at antenatal or maternity clinics. The feasibility and appropriateness of routine enquiry for domestic violence in various health care settings and communities in India should be explored in view of its effects on health outcomes.

\section{Strengths and limitations}

The data for this study were obtained from a large survey, providing rich information on the lives and circumstances of women in India. However, the cross-sectional nature of the survey means that the temporality of observed associations is difficult to establish. Some of the outcomes, such as a greater number of children born, may have occurred before exposure to violence, and, indeed, may have been a cause for the exposure to violence. While the rich NFHS-3 data set allowed a wide range of potential confounders to be included in the analysis, there is some potential for residual confounding due to unmeasured factors. The study uses the most recent national data available on the exposure to spousal violence and reproductive health of Indian women, yet they come from a 
survey conducted nearly a decade ago. The fourth National Family Health Survey was conducted between 2015 and 2016, and although the official report has been released, the data have not yet been made freely available for analysis at the time of writing [51]. As such, it cannot claim to be representative of the present situation in India.

The overall prevalence of emotional violence (14\%) in this study is lower than may be expected for this population. It is known that women are usually reluctant to disclose violence, regardless of the methods used to assess violence [1]. This may reflect under-reporting by participants, refusal to participate by those who experience violence, or a possibility that families of women experiencing violence were more likely to interrupt the interview (thus excluding them from analysis). The National Family Health Surveys include the domestic violence module as a part of a larger demographic and health survey. Although these contain a detailed module and attempt to ask specific questions about a wide range of factors related to violence, dedicated surveys for domestic violence are better suited to collect accurate information on partner violence than large surveys with a domestic violence component [52].

The Conflict Tactics Scale adapted for this survey is a widely used valid and reliable scale for assessment of partner violence [24, 53]. However, it does not measure emotional aspects of physical and sexual violence; it measures exposure to emotional violence by itself. There is, therefore, potential for some misclassification of the exposure and outcome, which would serve to underestimate the true effect. Spousal controlling behaviours may be deemed more culturally acceptable (or expected) and, therefore, are not considered abusive by many women in India $[39,54]$. The emotional violence questions do not capture this aspect of abuse, asking only about husbands insulting, threatening, or humiliating their wives. Cultural acceptability may also influence reporting, so that while women recognise the abusive nature of threatening, humiliating, or insulting behaviours (and may perhaps under-report), they may not consider a spouse who does not allow them to control their own money (for example) to be particularly negative and may feel more comfortable reporting it.

\section{Conclusion}

Emotional violence in the form of humiliating, insulting, or threatening behaviours is reported by nearly 1 in 7 of Indian women, most often in conjunction with physical and/or sexual violence. Spousal controlling behaviours are reported by more than a third of respondents. While spousal emotional violence does not appear to have a significant impact after the adverse effects of physical and sexual violence are accounted for, untangling the separate 
effects of different types of violence is challenging. An observed association between spousal emotional abuse in the form of controlling behaviours and adverse reproductive outcomes, in the absence of a statistically significant effect of spousal emotional violence, highlights the complexity of assessing the consequences of emotional abuse. It also highlights that the need to study the role spousal controlling behaviour plays in influencing women's health.

There remains an urgent need to explore the role of public health in addressing the issue of violence against women in India. If found feasible, spousal abuse screening in institutions of reproductive health care provision might be an effective intervention to address both problems. Violence against women is a social vice that not only hurts a vulnerable section of society; it also affects the health and lives of future generations. More importantly, it is a preventable problem, and one that must not be left unaddressed. The legal approach to tackling the problem of violence has traditionally been used. A public health approach to what was previously a purely legal framework of dealing with violence has often been discussed [55]. Preventive measures such as training people in non-violent resolution of disputes, and reducing access to weapons and alcohol are believed to be complementary to the judicial system $[55,56]$. The findings from this study indicate that prevention of violence can also have longterm public health benefits.

\section{Funding}

The initial analysis was conducted as part of ST's MSc Global Health Sciences, at the University of Oxford, where she was funded by an ExxonMobil Foundation studentship.

\section{References}

1. World Health Organization (2013) Global and regional estimates of violence against women: prevalence and health effects of intimate partner violence and non-partner sexual violence [Internet]. World Health Organization. http://www.who.int/iris/handle/10665/85239. Accessed 5 Dec 2016

2. Heise LL, Pitanguy J, Germain A (1994) Violence against women: the hidden health burden. World Bank Discussion Papers. https://www.scienceopen.com/document?vid=239b3a92-73c4-4a44-9563ec1d70832251. Accessed 5 Dec 2016

3. Devries KM, Mak JYT, García-Moreno C, Petzold M, Child JC, Falder G et al. Global health. The global prevalence of intimate partner violence 
against women. Science 2013 340(6140):1527-1528

4. Breiding MJ, Basile KC, Smith SG, Black MC, Mahendra R (2015)

Intimate partner violence surveillance: uniform definitions and recommended data elements. Version 2.0. Atlanta. Centers for Disease Control and Prevention, Georgia

5. Garcia-Moreno C, Jansen HAFM., Ellsberg M, Heise L, Watts CH, WHO Multi-country Study on Women's Health and Domestic Violence against Women Study Team (2006) Prevalence of intimate partner violence: findings from the WHO multi-country study on women's health and domestic violence. Lancet Lond Engl 368(9543):1260-1269

6. Krug EG, Mercy JA, Dahlberg LL, Zwi AB (2002) The world report on violence and health. Lancet Lond Engl 360(9339):1083-1088

7. Karakurt G, Silver KE (2013) Emotional abuse in intimate relationships: the role of gender and age. Violence Vict 28(5):804-821

8. Sarkar NN (2008) The impact of intimate partner violence on women's reproductive health and pregnancy outcome. J Obstet Gynaecol 28(3):266271

9. Bloom SS, Wypij D, Gupta MD (2001) Dimensions of women's autonomy and the influence on maternal health care utilization in a north indian city. Demography 38(1):67-78

10. Morgan SP, Stash S, Smith HL, Mason KO (2002) Muslim and nonMuslim differences in female autonomy and fertility: evidence from four Asian countries. Popul Dev Rev 28(3):515-537

11. Fotso J-C, Ezeh AC, Essendi H (2009) Maternal health in resource-poor urban settings: how does women's autonomy influence the utilization of obstetric care services? Reprod Health 6:9

12. Coker AL, Smith PH, Bethea L, King MR, McKeown RE (2000) Physical health consequences of physical and psychological intimate partner violence. Arch Fam Med 9(5):451

13. Campbell J, Torres S, Ryan J, King C, Campbell DW, Stallings RY et al (1999) Physical and nonphysical partner abuse and other risk factors for low 
birth weight among full term and preterm Babiesa multiethnic case-control study. Am J Epidemiol 150(7):714-726

14. Babu BV, Kar SK (2009) Domestic violence against women in eastern India: a population-based study on prevalence and related issues. BMC Public Health 9:129

15. Kimuna SR, Djamba YK, Ciciurkaite G, Cherukuri S (2013) Domestic violence in India: insights from the 2005-2006 national family health survey. J Interpers Violence 28(4):773-807

16. Martin SL, Kilgallen B, Tsui AO, Maitra K, Singh KK, Kupper LL (1999) Sexual behaviors and reproductive health outcomes: associations with wife abuse in India. JAMA 282(20):1967-1972

17. Koski AD, Stephenson R, Koenig MR (2011) Physical violence by partner during pregnancy and use of prenatal care in rural India. J Health Popul Nutr 29(3):245-254

18. Shah PS, Shah J, Knowledge Synthesis Group on Determinants of Preterm/LBW Births (2010) Maternal exposure to domestic violence and pregnancy and birth outcomes: a systematic review and meta-analyses. J Womens Health 19(11):2017-2031

19. Silverman JG, Decker MR, Reed E, Raj A (2006) Intimate partner violence around the time of pregnancy: association with breastfeeding behavior. J Womens Health 15(8):934-940

20. Begum S, Dwivedi S, Pandey A, Mittal S (2010) Association between domestic violence and unintended pregnancies in India: findings from the National Family Health Survey-2 data. Natl Med J India 23(4):198-200

21. Silverman JG, Decker MR, Cheng DM, Wirth K, Saggurti N, McCauley HL et al (2011) Gender-based disparities in infant and child mortality based on maternal exposure to spousal violence: the heavy burden borne by Indian girls. Arch Pediatr Adolesc Med 165(1):22-27

22. National Family Health Survey India-3 [Internet]. http://www.nfhsindia.org/nfhs3.html

23. National Family Health Survey (NFHS-3) (2007) 2005-2006. Mumbai: International Institute for Population Sciences (IIPS) and Macro International 
24. Straus MA, Hamby SL, BONEY-McCOY SUE, Sugarman DB (1996) The revised conflict tactics scales (CTS2) development and preliminary psychometric data. J Fam Issues 17(3):283-316

25. Saha UC, Saha KB (2010) A trend in women's health in India-what has been achieved and what can be done. Rural Remote Health 10(2):1260

26. Srinivasan S (2007) Population policy and programme in India: A review. Soc Change 37(1):125-136

27. Swahnberg K, Wijma B, Schei B, Hilden M, Irminger K, Wingren GB (2004) Are sociodemographic and regional and sample factors associated with prevalence of abuse? Acta Obstet Gynecol Scand 83(3):276-288

28. McNamee R (2005) Regression modelling and other methods to control confounding. Occup Environ Med 62(7):500-506

29. Maldonado G, Greenland S (1993) Simulation study of confounderselection strategies. Am J Epidemiol 138(11):923-936

30. Data Analysis and Statistical Software|Stata [Internet]. http://www.stata.com/. Accessed 6 Dec 2016

31. Sørbø MF, Grimstad H, Bjørngaard JH, Schei B, Lukasse M (2013) Prevalence of sexual, physical and emotional abuse in the Norwegian mother and child cohort study. BMC Public Health 13:186

32. Villarreal A (2007) Women's employment status, coercive control, and intimate partner violence in Mexico. J Marriage Fam 69(2):418-434

33. Lawoko S, Dalal K, Jiayou L, Jansson B (2007) Social inequalities in intimate partner violence: a study of women in Kenya. Violence Vict 22(6):773-784

34. Mahapatro M, Gupta RN, Gupta V (2012) The risk factor of domestic violence in India. Indian J Community Med 37(3):153

35. Jejeebhoy SJ, Sathar ZA (2001) Women's autonomy in India and Pakistan: the influence of religion and region. Popul Dev Rev 27(4):687-712

36. Silverman JG, Gupta J, Decker MR, Kapur N, Raj A (2007) Intimate partner violence and unwanted pregnancy, miscarriage, induced abortion, and 
stillbirth among a national sample of Bangladeshi women. BJOG Int J Obstet Gynaecol 114(10):1246-1252

37. Campbell JC (2002) Health consequences of intimate partner violence. Lancet 359(9314):1331-1336

38. Stephenson R, Winter A, Hindin M (2013) Frequency of intimate partner violence and rural women's mental health in four Indian states. Violence Women 19(9):1133-1150

39. Koenig MA, Stephenson R, Ahmed S, Jejeebhoy SJ, Campbell J (2006) Individual and contextual determinants of domestic violence in North India. Am J Public Health 96(1):132-138

40. Sabarwal S, Santhya KG, Jejeebhoy SJ (2014) Women's autonomy and experience of physical violence within marriage in rural India: evidence from a prospective study. J Interpers Violence 29(2):332-347

41. Go VF, Johnson SC, Bentley ME, Sivaram S, Srikrishnan AK, Celentano DD et al (2003) Crossing the threshold. Cult Health Sex 5(5):393-408

42. Jejeebhoy SJ, Cook RJ (1997) State accountability for wife-beating: the Indian challenge. Lancet Lond Engl 349(Suppl 1):sI10-12

43. Rahman M, Nakamura K, Seino K, Kizuki M (2012) Intimate partner violence and use of reproductive health services among married women: evidence from a national Bangladeshi sample. BMC Public Health 12:913

44. Dalal K, Shabnam J, Andrews-Chavez J, Martensson LB, Timpka T (2012) Economic empowerment of women and utilization of maternal delivery care in Bangladesh. Int J Prev Med 3(9):628-636

45. Ulrich YC, Cain KC, Sugg NK, Rivara FP, Rubanowice DM, Thompson RS (2003) Medical care utilization patterns in women with diagnosed domestic violence. Am J Prev Med 24(1):9-15

46. Bonomi AE, Anderson ML, Rivara FP, Thompson RS (2009) Health care utilization and costs associated with physical and nonphysical-only intimate partner violence. Health Serv Res 44(3):1052-1067

47. Emenike E, Lawoko S, Dalal K (2008) Intimate partner violence and reproductive health of women in Kenya. Int Nurs Rev 55(1):97-102 
48. Wokoma TT, Jampala M, Bexhell H, Guthrie K, Lindow S (2014) A comparative study of the prevalence of domestic violence in women requesting a termination of pregnancy and those attending the antenatal clinic. BJOG Int J Obstet Gynaecol 121(5):627-633

49. Feder G, Ramsay J, Dunne D, Rose M, Arsene C, Norman R et al (2009) How far does screening women for domestic (partner) violence in different health-care settings meet criteria for a screening programme? Systematic reviews of nine UK National Screening Committee criteria. Health Technol Assess Winch Engl 13(16):iii-iv, xi-xiii, 1-113, 137-347

50. Bacchus L, Mezey G, Bewley S (2002) Women's perceptions and experiences of routine enquiry for domestic violence in a maternity service. BJOG Int J Obstet Gynaecol 109(1):9-16

51. High Demand for New India NFHS-4 Data|The DHS Program Blog [Internet]. http://blog.dhsprogram.com/high-demand-nfhs4/. Accessed 19 Sep 2017

52. "Violence against women: a statistical overview, challenges and gaps in data collection and methodology and approaches for overcoming them"Expert Group Meeting [Internet].

http://www.un.org/womenwatch/daw/egm/vaw-stat-2005/documents.html. Accessed 6 Dec 2016

53. Janssen PA, Holt VL, Sugg NK, Emanuel I, Critchlow CM, Henderson AD (2003) Intimate partner violence and adverse pregnancy outcomes: a population-based study. Am J Obstet Gynecol 188(5):1341-1347

54. Faramarzi M, Esmailzadeh S, Mosavi S (2005) A comparison of abused and non-abused women's definitions of domestic violence and attitudes to acceptance of male dominance. Eur J Obstet Gynecol Reprod Biol 122(2):225-231

55. Moore MH (1995) Public health and criminal justice approaches to prevention. Crime Justice 19:237-262

56. Mercy JA, Rosenberg ML, Powell KE, Broome CV, Roper WL (1993) Public health policy for preventing violence. Health Aff (Millwood) 12(4):729 